\title{
Bioactivity of Essential Oil of Artemisia argyi Lévl. et Van. and Its Main Compounds Against Lasioderma serricorne
}

\author{
Wen-Juan Zhang ${ }^{1}$, Chun-Xue You ${ }^{1}$, Kai Yang ${ }^{1}$, Ran Chen ${ }^{1}$, Ying Wang ${ }^{1}$, Yan Wu², \\ Zhu-Feng Geng ${ }^{3}$, Hai-Ping Chen ${ }^{4}$, Hai-Yan Jiang ${ }^{4}$, Yang Su ${ }^{5}$, Ning Lei ${ }^{6}$, Ping $\mathrm{Ma}^{6}$, \\ Shu-Shan $\mathrm{Du}^{1 *}$ and Zhi-Wei Deng ${ }^{3}$ \\ ${ }^{1}$ Protection and Utilization of Traditional Chinese Medicine of Beijing Area Major Laboratory, College of Resources Science and Technology, \\ Beijing Normal University (NO.19 Xinjiekouwai Street, Beijing 100875, CHINA) \\ ${ }^{2}$ Technical Center of China Tobacco Guangxi Industrial Co., Ltd (Nanning 530001, Guangxi, CHINA) \\ ${ }^{3}$ Analytical and Testing Center, Beijing Normal University (NO.19 Xinjiekouwai Street, Beijing 100875, CHINA) \\ ${ }^{4}$ College of Pharmacy, Liaoning University of Traditional Chinese Medicine (Dalian 116600, Liaoning, CHINA) \\ ${ }^{5}$ College of Clinical Medicine Sicence, Tibet University (NO.36 Jiangsu Road, Lhasa 850000, Tibet Autonomous Region, CHINA) \\ ${ }^{6}$ Department of Pharmacy General Hospital of Second Artillery, PLA (NO.16 Xinjiekouwai Street, Beijing 100088, CHINA)
}

\begin{abstract}
Artemisia argyi Lévl. et Van., a perennial herb with a strong volatile odor, is widely distrbuted in the world. Essential oil obtained from Artemisia argyi was analyzed by gas chromatography-mass spectrometry (GC-MS). A total of 32 components representing $91.74 \%$ of the total oil were identified and the main compounds in the oil were found to be eucalyptol $(22.03 \%), \beta$-pinene $(14.53 \%), \beta$-caryophyllene $(9.24 \%)$ and (-)-camphor (5.45\%). With a further isolation, four active constituents were obtained from the essential oil and identified as eucalyptol, $\beta$-pinene, $\beta$-caryophyllene and camphor. The essential oil and the four isolated compounds exhibited potential bioactivity against Lasioderma serricorne adults. In the progress of assay, it showed that the essential oil, camphor, eucalyptol, $\beta$-caryophyllene and $\beta$-pinene exhibited strong contact toxicity against $L$. serricorne adults with $\mathrm{LD}_{50}$ values of $6.42,11.30,15.58,35.52$, and $65.55 \mu \mathrm{g} / \mathrm{adult}$, respectively. During the fumigant toxicity test, the essential oil, eucalyptol and camphor showed stronger fumigant toxicity against $L$. serricorne adults than $\beta$-pinene $\left(\mathrm{LC}_{50}=29.03 \mathrm{mg} / \mathrm{L}\right.$ air $)$ with $\mathrm{LC}_{50}$ values of 8.04 , 5.18 and $2.91 \mathrm{mg} / \mathrm{L}$ air. Moreover, the essential oil, eucalyptol, $\beta$-pinene and camphor also exhibited the strong repellency against $L$. serricorne adults, while, $\beta$-caryophyllene exhibited attracting activity relative to the positive control, DEET. The study revealed that the bioactivity properties of the essential oil can be attributed to the synergistic effects of its diverse major and minor components. The results indicate that the essential oil of $A$. argyi and the isolated compounds have potential to be developed into natural insecticides, fumigants or repellents in controlling insects in stored grains and traditional Chinese medicinal materials.
\end{abstract}

Key words: $L$. serricorne, $A$. argyi, antagonistic storage, bioactivity, essential compound

\section{INTRODUCTION}

Antagonistic storage has been used as one of traditional Chinese medicinal materials conservation methods. It mainly utilizes some traditional Chinese medicinal materials having special volatile odor to store with medicinal materials vulnerable to insects, so as to prevent the insects. With the improvement of the sense of environmental protection and medication security, it is believed that this method would have broad prospects of application in the future. In order to inherit and develop the traditional method of prevention and control of stored grain insects, we took Artemisia argyi as research object and Lasioderma serricorne adults as the target insects. It was expected that this research work would provide some theoretical basis for the conception of antagonistic storage.

Abbreviations: A. argyi: Artemisia argyi; L. serricorne: Lasioderma serricorne; RI: Retention Index; MS: mass spectrum; DEET: N,N-diethyl-3-methyl-benzamide.

\footnotetext{
* Correspondence to: Shu-Shan Du, Protection and Utilization of Traditional Chinese Medicine of Beijing Area Major Laboratory, College of Resources Science and Technology, Beijing Normal University, NO.19 Xinjiekouwei Street, Beijing 100875, CHINA E-mail: dushushan@ bnu.edu.cn Accepted April 26, 2014 (received for review March 31, 2014) Journal of Oleo Science ISSN 1345-8957 print / ISSN 1347-3352 online http://www.jstage.jst.go.jp/browse/jos/ http://mc.manusriptcentral.com/jjocs
} 
The cigarette beetle Lasioderma serricome (Frbricius) (Coleoptera: Anobiidae) is widely distributed and is of considerable economic importance in tropical to temperate climates $^{1)}$. This beetle is destructive primary insect pests of stored cereals, tobacco, oilseeds, dried fruits and traditional Chinese medicinal materials ${ }^{2}$. Development and survival are affected by type of food, temperature and humidity, therefore the life cycle is different ${ }^{1}$. Currently, recommended pest control measures in durable stored products rely heavily on the use of synthetic insecticides or fumigants which pose possible health hazards to warm-blooded animals, risk of environmental pollution, development of resistance by insects and pest resurgence ${ }^{3)}$. These problems have necessitated a search for alternative ecologically safe insect pest control methods ${ }^{4)}$. The use of essential oils or their constituents with low mammalian toxicity can effectively prevent insect pest especially in storage ${ }^{5)}$. Investigations in several countries confirm that some plant essential oils not only repel insects, but also possess contact and fumigant toxicity against stored product pests as well as exhibiting feeding inhibition or harmful effects on the reproductive system of insects ${ }^{6}$. Essential oils and their constituents of many plants including medicinal herbs, spices and fruits have been evaluated successfully for insecticidal or repellent activity against stored product insects, they have been proven more effective than traditionally used pesticides in some $\operatorname{cases}^{7-16)}$.

Besides insecticidal and repellent activity, essential oils from different plant sources have exhibited several biological activities, including antimicrobial ${ }^{17)}$ and antifungal ${ }^{18)}$, nematicidal $^{19)}$, larvicidal $^{20,21)}$, and acaricidal $^{22)}$. As a consequence, this vast arsenal of bioactive compounds has attracted significant and crescent attention of researchers in recent years. During our screening program for new agrochemicals from Chinese medicinal herbs and wild plants, the essential oil of Artemisia argyi aerial parts was found to possess insecticidal toxicity against $L$. serricorne adults. A. argyi is a genus of annual herb in the Lamiaceae family. Artemisia species, widespread throughout the world, are important medicinal plants which are receiving phytochemical attention due to their biological and chemical diversities ${ }^{23)}$.

A. argyi has been commonly used as a kind of traditional Chinese medicine in China for a very long history ${ }^{24)}$. It is one of the most popular plants in Chinese traditional preparations and frequently used for the treatment for the diseases such as malaria, hepatitis, cancer, inflammation, and infections by fungi, bacteria and viruses ${ }^{25,26}$. The biological activities of essential oils extracted from $A$. argyi leaves have been studied. For example, the essential oil from leaves of $A$. argyi is reported to show anti-histamatic effect and antifungal activity ${ }^{24)}$. Recently, the chemical composition of essential oil extracted from leaves or flowers of $A$. argyi has been reported ${ }^{23)}$. However, the re- pellent and insecticidal activity of essential oil extracted from $A$. argyi aerial parts against $L$. serricorne has never been explored. Hence we decided to investigate the chemical constituents, repellent and insecticidal activity of the essential oil against $L$. serricorne and isolated of active constituent compounds from the essential oil for the first time.

\section{EXPERIMENTAL PROCEDURES}

\subsection{Chemicals}

Eucalyptol, $\beta$-pinene, $\beta$-caryophyllene and camphor were isolated from $A$. argyi essential oil on a silica gel column $(45 \mathrm{~mm} \times 500 \mathrm{~mm}$ ) (Qingdao Marine Chemical Plant, Shandong province, China).

\subsection{Material}

\subsubsection{Plants}

Dried aerial parts $(2.0 \mathrm{~kg})$ of $A$. argyi were collected in October 2013 in Jining City $\left(35.23^{\circ} \mathrm{N}\right.$ latitude and $116.33^{\circ} \mathrm{E}$ longitude), Shandong province of China. The aerial parts were air-dried for one week and ground to a powder. The plant was identified by Dr. Liu, Q.R. (College of Life Sciences, Beijing Normal University, Beijing, China) and a voucher specimen (BNU-CMH-Dushuahan-2013-10-22-006) was deposited at the Herbarium (BNU) of College of Life Sciences, Beijing Normal University.

2.2.2 Insects

The cigarette beetle Lasioderma serricorne were obtained from laboratory cultures maintained for the last 2 years in dark in incubators at $29 \pm 1{ }^{\circ} \mathrm{C}$ and $70-80 \%$ relative humidity. The insects were reared in glass containers $(0.5$ L) containing wheat flour at $12-13 \%$ moisture content mixed with yeast $(10: 1, w / w)$. Adults used in all the experiments were about $7 \pm 2$ days old.

\subsection{Isolation of the Essential Oil and Purification of Four Constitunent Compounds}

The powder $(2.0 \mathrm{~kg})$ of $A$. argyi aerial parts was subjected to hydrodistillation using a modified Clevenger-type apparatus for $6 \mathrm{~h}$. Anhydrous sodium sulphate was used to remove water after extraction. The essential oil $(9.1 \mathrm{~g})$ with a yield of $0.50 \%(\mathrm{v} / \mathrm{w})$ was stored in airtight containers in a refrigerator at $4^{\circ} \mathrm{C}$ for subsequent experiments. The crude essential oil $(8 \mathrm{~mL})$ was chromatographed on a silica gel column $(45 \times 500 \mathrm{~mm})$ (Qingdao Marine Chemical Plant, Shandong province, China) by gradient elution with n-hexane first, then with n-hexane-ethyl acetate, and last with ethyl acetate. Fractions $(120 \mathrm{~mL}$ ) were collected and concentrated at $35^{\circ} \mathrm{C}$, and similar fractions according to thin layer chromatography (TLC) profiles were combined to yield 20 fractions. Fractions $(4-7,11-15)$ that possessed contact toxicity, with similar TLC profiles, were pooled and 
further purified by preparative silica gel column chromatography (PTLC) until the pure compounds for determining structure as eucalyptol (1, $1.05 \mathrm{~g}), \beta$-pinene $(2,0.65 \mathrm{~g})$, camphor $(4,0.26 \mathrm{~g}), \beta$-caryophyllene $(3,0.36 \mathrm{~g})$ were obtained. The isolated compounds were elucidated based on nuclear magnetic resonance. ${ }^{1} \mathrm{H}$ and ${ }^{13} \mathrm{C}-\mathrm{NMR}$ spectra were recorded on Bruker Avance DRX 500 instruments using $\mathrm{CDCl}_{3}$ as solvent with TMS as internal standard.

\subsection{GC-FID and GC-MS analysis}

GC-MS analysis was performed on a Thermo Finnigan Trace DSQ instrument equipped with a flame ionization detector and a HP-5MS $(30 \mathrm{~m} \times 0.25 \mathrm{~mm} \times 0.25 \mu \mathrm{m})$ capillary column. The column temperature was programmed at $50^{\circ} \mathrm{C}$ for $2 \mathrm{~min}$, then increased at $2^{\circ} \mathrm{C} / \mathrm{min}$ to the temperature of $150^{\circ} \mathrm{C}$ and held for $2 \mathrm{~min}$, and then increased at $10^{\circ} \mathrm{C} / \mathrm{min}$ until the final temperature of $250^{\circ} \mathrm{C}$ was reached, where it was held for $5 \mathrm{~min}$. The injector temperature was maintained at $250^{\circ} \mathrm{C}$ and the volume injected was $0.1 \mathrm{~mL}$ of $1 \%$ solution (diluted in n-hexane). The carrier gas was helium at flow rate of $1.0 \mathrm{~mL} / \mathrm{min}$. Spectra were scanned from 50 to $550 \mathrm{~m} / \mathrm{z}$. Most constituents were identified by comparison of their retention indices with those reported in the literatures. The retention indices were determined in relation to a homologous series of n-alkanes $\left(\mathrm{C}_{5}-\mathrm{C}_{36}\right)$ under the same operating conditions. Further identification was made by comparison of their mass spectra with those stored in NIST 05 and Wiley 275 libraries or with mass spectra from literature ${ }^{28)}$. Relative percentages of the individual components of the essential oil were obtained by averaging the GC peak area\% reports.

\subsection{Isolated Constituent Compounds}

Eucalyptol (1, Fig. 1). Colorless oil. ${ }^{1} \mathrm{H}-\mathrm{NMR}(500 \mathrm{MHz}$, $\left.\mathrm{CDCl}_{3}\right) \delta$ ppm: $2.03(2 \mathrm{H}, \mathrm{t}, \mathrm{H}-2), 1.68(2 \mathrm{H}, \mathrm{t}, \mathrm{H}-6), 1.52(4 \mathrm{H}$, m, H-3, 5), $1.42(1 \mathrm{H}, \mathrm{m}, \mathrm{H}-4), 1.25(6 \mathrm{H}, \mathrm{s}, \mathrm{H}-9,10), 1.07$ $(3 \mathrm{H}, \mathrm{s}, \mathrm{H}-7) ;{ }^{13} \mathrm{C}-\mathrm{NMR}\left(125 \mathrm{MHz}, \mathrm{CDCl}_{3}\right) \delta$ ppm: $73.61(\mathrm{C}-8)$, $69.77(\mathrm{C}-1), 32.94(\mathrm{C}-4), 31.51(\mathrm{C}-3,5), 28.89(\mathrm{C}-2,6)$, 27.58 (C-7) , 22.83 (C-9, 10). The ${ }^{1} \mathrm{H}$ and ${ }^{13} \mathrm{C}-\mathrm{NMR}$ data were in agreement with the reported data ${ }^{29)}$.

$\beta$-Pinene (2, Fig. 1). Colorless oil. ${ }^{1} \mathrm{H}-\mathrm{NMR}$ (500 MHz,
$\left.\mathrm{CDCl}_{3}\right) \delta$ ppm: $4.65(1 \mathrm{H}, \mathrm{s}, \mathrm{H}-10 \beta), 4.58(1 \mathrm{H}, \mathrm{s}, \mathrm{H}-10 \alpha), 2.57$ $(1 \mathrm{H}, \mathrm{m}, \mathrm{H}-3 \beta), 2.49(1 \mathrm{H}, \mathrm{t}, J=5.0 \mathrm{~Hz}, \mathrm{H}-1), 2.33(1 \mathrm{H}, \mathrm{m}$, H-7 $\beta$ ), 2.26 ( $1 \mathrm{H}, \mathrm{dd}, J=10.0 \mathrm{~Hz}, \mathrm{H}-3 \alpha), 2.00$ (1H, m, H-5), $1.85(1 \mathrm{H}, \mathrm{m}, \mathrm{H}-4 \beta), 1.85(1 \mathrm{H}, \mathrm{m}, \mathrm{H}-4 \alpha), 1.44(1 \mathrm{H}, \mathrm{d}, J=10.0$ $\mathrm{Hz}, \mathrm{H}-7 \alpha), 1.26(3 \mathrm{H}, \mathrm{s}, \mathrm{Me}-8), 0.74(3 \mathrm{H}, \mathrm{s}, \mathrm{Me}-9) ;{ }^{13} \mathrm{C}-\mathrm{NMR}$ $\left(125 \mathrm{MHz} \mathrm{CDCl}_{3}\right) \delta$ ppm: $152.4(\mathrm{C}-2), 105.9(\mathrm{C}-10), 51.8$ (C-1) , 40.7 (C-6), 40.4(C-5), 27.0 (C-7), 26.1 (C-8), 23.6 (C-3), 23.6 (C-4), 21.8(C-9). Its NMR data were identical to the literature data $^{30)}$.

Camphor (3, Fig. 1). Colorless crystal. ${ }^{1} \mathrm{H}-\mathrm{NMR}(500$ $\left.\mathrm{MHz}, \mathrm{CDCl}_{3}\right) \delta$ ppm: $2.37(1 \mathrm{H}, \mathrm{m}, \mathrm{H}-3 \mathrm{~b}), 2.11(1 \mathrm{H}, \mathrm{t}, J=4.5$ $\mathrm{Hz}, \mathrm{H}-6 \mathrm{a}), 1.96(1 \mathrm{H}, \mathrm{m}, \mathrm{H}-4), 1.87(1 \mathrm{H}, \mathrm{d}, J=18.0 \mathrm{~Hz}$, H-3a), 1.70 (1H, m, H-6a), $1.39(2 \mathrm{H}, \mathrm{m}, \mathrm{H}-5), 0.98(3 \mathrm{H}, \mathrm{s}$, Me-8), $0.93(3 \mathrm{H}, \mathrm{s}, \mathrm{Me}-10), 0.85(3 \mathrm{H}, \mathrm{s}, \mathrm{Me}-10) ;{ }^{13} \mathrm{C}-\mathrm{NMR}$ $\left(125 \mathrm{MHz}, \mathrm{CDCl}_{3}\right) \delta$ ppm: $219.83(\mathrm{C}-6), 57.74(\mathrm{C}-1), 46.82$ (C-7), 43.33(C-5), $43.05(\mathrm{C}-4), 29.92(\mathrm{C}-2), 27.06(\mathrm{C}-8)$, 19.81 (C-3), 19.17 (C-9), 9.28(C-10). The ${ }^{1} \mathrm{H}$ and ${ }^{13} \mathrm{C}-\mathrm{NMR}$ data were in accord with the reported data ${ }^{31)}$.

$\beta$-Caryophyllene (4, Fig. 1). Colorless oil. ${ }^{1} \mathrm{H}-\mathrm{NMR}(500$ $\left.\mathrm{MHz}, \mathrm{CDCl}_{3}\right) \delta$ ppm: 5.33(1H, m, H-5), $4.97(1 \mathrm{H}, \mathrm{s}, \mathrm{H}-12 \mathrm{a})$, $4.85(1 \mathrm{H}, \mathrm{s}, \mathrm{H}-12 \mathrm{~b}), 2.37$ (1H, m, H-9), $2.33(1 \mathrm{H}, \mathrm{m}, \mathrm{H}-7 \mathrm{~b})$, $2.23(1 \mathrm{H}, \mathrm{m}, \mathrm{H}-7 \mathrm{a}), 2.11(1 \mathrm{H}, \mathrm{m}, \mathrm{H}-1), 2.02(1 \mathrm{H}, \mathrm{m}, \mathrm{H}-6 \mathrm{~b})$, $1.94(1 \mathrm{H}, \mathrm{m}, \mathrm{H}-6 \mathrm{a}), 1.72(1 \mathrm{H}, \mathrm{m}, \mathrm{H}-2 \mathrm{~b}), 1.69$ (1H, m, H-3b), 1.65-1.67 (2H, m, H-10), 1.64(3H, s, Me-15), $1.60(1 \mathrm{H}, \mathrm{m}$, H-3a), 1.52 (1H, m, H-2a), $1.02(3 \mathrm{H}, \mathrm{s}, \mathrm{Me}-12), 1.00(3 \mathrm{H}, \mathrm{s}$, $\mathrm{Me}-13) ;{ }^{13} \mathrm{C}-\mathrm{NMR}\left(125 \mathrm{MHz}, \mathrm{CDCl}_{3}\right) \delta \mathrm{ppm}: 154.74(\mathrm{C}-2)$, 135.58 (C-6), 124.31 (C-5), 111.67 (C-12), 53.54 (C-9), $48.48(\mathrm{C}-1), 40.33(\mathrm{C}-11), 39.96(\mathrm{C}-7), 34.79(\mathrm{C}-3), 33.02$ (C-10), 30.09 (C-13), 29.36 (C-8), 28.38 (C-4), 22.66 (C-14), 16.32 (C-15). The ${ }^{1} \mathrm{H}$ and ${ }^{13} \mathrm{C}-\mathrm{NMR}$ data were consistent with the literature data ${ }^{32)}$.

\subsection{Bioactivity}

2.6.1 Insecticidial activity

2.6.1.1 Contact Toxicity

The contact toxicity of the essential oil/pure compounds against $L$. serricorne adults was tested as described by Liu and $\mathrm{Ho}^{33)}$. Range-finding studies were run to determine the appropriate testing concentrations. A serial dilution of the essential oil/compounds (five concentrations) was prepared in $n$-hexane. Aliquots of $0.5 \mu \mathrm{L}$ of the dilutions were

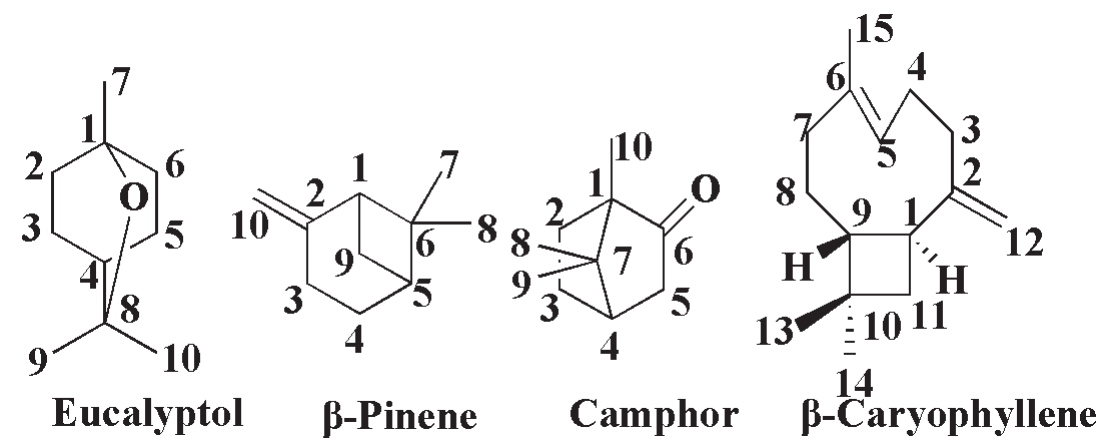

Fig. 1 Constituent compounds isolated from the essential oil of $A$. argyi aerial parts. 
applied topically to the dorsal thorax of the insects. Controls were determined using $n$-hexane. Five replicates were carried out for all treatments and controls. Both treated and control insects were then transferred to glass vials (diameter $2.5 \mathrm{~cm}$, height $5.5 \mathrm{~cm}$, volume $25 \mathrm{~mL}$ ) (10 insects/vial) with culture media and kept in incubators (29-30 ${ }^{\circ} \mathrm{C}$ and $70-80 \%$ r.h). Mortality of insects was observed after $24 \mathrm{~h}$. The observed mortality data were corrected for control mortality using Abbott's formula. The $\mathrm{LD}_{50}$ values were calculated by using Probit analysis ${ }^{34)}$ (IBM SPSS V20.0).

\subsubsection{Fumigant Toxicity}

The fumigant activity of the essential oil and the pure compounds against $L$. serricome adults was tested as described by Liu and $\mathrm{Ho}^{33)}$. Range-finding studies were run to determine the appropriate testing concentrations. A serial dilution of the essential oil/compounds (five concentrations) was prepared in $n$-hexane. A Whatman filter paper (diameter $2.0 \mathrm{~cm}$ ) was impregnated with $10 \mu \mathrm{L}$ dilution, and then placed on the underside of the screw cap of a glass vial (diameter $2.5 \mathrm{~cm}$, height $5.5 \mathrm{~cm}$, volume $25 \mathrm{~mL}$ ). The solvent was allowed to evaporate for $20 \mathrm{~s}$ before the cap was placed tightly on the glass vial, each of which contained 10 insects to form a sealed chamber. Preliminary experiments demonstrated that $20 \mathrm{~s}$ was sufficient for the evaporation of solvents. $n$-Hexane was used as a control. Five replicates were carried out for all treatments and controls and they were incubated for $24 \mathrm{~h}\left(29-30^{\circ} \mathrm{C}\right.$ and $70-80 \%$ r.h). The insects were then transferred to clean vials with some culture media and returned to the incubator for $24 \mathrm{~h}$. Mortality of insects was observed and results from all replicates were calculated by using Probit analysis to determine $\mathrm{LC}_{50}$ values (IBM SPSS V20.0) ${ }^{34)}$.

\subsubsection{Repellency tests}

The repellent activity to Lasioderma serricorne adults was tested using the area preference method ${ }^{14)}$. Petri dishes (9 cm in diameter) were used to confine red flour beetles and cigarette beetles during the experiment. The crude essential oil and the isolated compounds were diluted in $n$-hexane to five concentrations (39.3, 7.9, 1.6, 0.31 and $\left.0.06 \mathrm{~nL} / \mathrm{cm}^{2}\right)$, and $n$-hexane was used as the control. Filter paper $(9 \mathrm{~cm}$ in diameter $)$ was cut in half and $500 \mu \mathrm{l}$ of each concentration was applied separately to half of the filter paper as uniformly as possible with a micropipette. The other half (control) was treated with $500 \mu$ l of $n$ hexane. Both the treated half and the control half were then air-dried to evaporate the solvent completely (30 s). A full disk was carefully remade by attaching the tested half to the negative control half with tape. Care was taken so that the attachment did not prevent free movement of insects from the one half to the other, but the distance between the filter paper halves remained sufficient to prevent seepage of test samples from one half to the other. Each remade filter paper after treatment with solid glue was placed in a Petri dish with the seam oriented in one of four randomly selected different directions to avoid any insecticidal stimuli affecting the distribution of insects. Twenty insects were released in the center of each filter paper disk, and a cover was placed over the Petri dish. Five replicates were used and the experiment was repeated three times. Counts of the insects present on each strip were made after 2 and $4 \mathrm{~h}$. The percent repellency (PR) of each volatile oil/compound was then calculated using the formula:

$$
\operatorname{PR}(\%)=[(\mathrm{Nc}-\mathrm{Nt}) /(\mathrm{Nc}+\mathrm{Nt})] \times 100
$$

$\mathrm{Nc}$ is the number of insects present in the negative control half while $\mathrm{Nt}$ is the number of insects present in the treated half. Analysis of variance (One-Way ANOVA and GLM Univariate) and Tukey's test were conducted by using SPSS 20.0 for Windows 2007. Percentage was subjected to an arcsine square-root transformation before variance and Tukey's tests. The averages were then assigned to different classes $\left(0\right.$ to V) in Table $1^{35)}$. A commercial repellent, DEET (N,N-diethyl-3-methyl- benzamide), was purchased from Dr. Ehrenstorfer, Germany and used as a positive control.

\section{RESULTS and DISCUSSION}

\subsection{Chemical compounds of the essential oil}

The $A$. argyi essential oil was dark blue with a density of $0.91 \mathrm{~g} / \mathrm{mL}$. The oil sample was analyzed by GC-FID and GC-MS, and the components were identified based on their RI values as well as by comparing their mass spectra with those reported in literature. GC-MS analysis of $A$. argyi essential oil revealed 32 components representing $91.74 \%$ of the oil (Table 2). The main composition of the oil was as follows: eucalyptol (22.03\%), $\beta$-pinene (14.53\%), $\beta$-caryophyllene $(9.24 \%),(-)$-camphor $(5.45 \%)$, germacrene D $(5.32 \%)$, thujone $(5.14 \%)$ and chamazulene $(5.06 \%)$.

Table 1 The scale to be assign repellency of the essential oil of $A$. argyi aerial parts and its constituents.

\begin{tabular}{cccccc}
\hline Class & Percent repellency & Class & Percent repellency & Class & Percent repellency \\
\hline 0 & $>0.01$ to $<0.1$ & II & $20.1-40$ & IV & $60.1-80$ \\
I & $0.1-20$ & III & $40.1-60$ & V & $80.1-100$ \\
\hline
\end{tabular}


Table 2 Chemical components of the essential oil of $A$. argyi.

\begin{tabular}{|c|c|c|c|c|}
\hline Peak no. & Components & $\mathrm{RI}^{\mathrm{a}}$ & $\% \mathrm{RA}^{\mathrm{b}}$ & Identification Methods $^{\mathrm{c}}$ \\
\hline 1 & o-Xylene & 871 & 0.21 & MS, RI \\
\hline 2 & $\alpha$-Phellandrene & 1184 & 0.68 & MS, RI, Co \\
\hline 3 & 1R- $\alpha$-Pinene & 1205 & 1.13 & MS, RI \\
\hline 4 & Camphene & 1256 & 0.51 & MS, RI \\
\hline 5 & $\beta$-Pinene & 1357 & 14.53 & MS, RI \\
\hline 6 & $\alpha$-Pinene & 1438 & 0.67 & MS, RI \\
\hline 7 & $(+)$-4-Carene & 1541 & 0.73 & MS, RI \\
\hline 8 & 2-Isopropyltoluene & 1576 & 0.56 & MS, RI \\
\hline 9 & Eucalyptol & 1600 & 22.03 & MS, RI \\
\hline 10 & Crithmene & 1739 & 1.30 & MS, RI \\
\hline 11 & Fenchene & 1676 & 0.22 & MS, RI \\
\hline 12 & Terpinolene & 1883 & 0.30 & MS, RI \\
\hline 13 & Linalool & 1451 & 0.32 & MS, RI \\
\hline 14 & Thujone & 1963 & 5.14 & MS, RI \\
\hline 15 & (-)-Camphor & 2151 & 5.45 & MS, RI \\
\hline 16 & L(-)-Borneol & 2268 & 1.01 & MS, RI \\
\hline 17 & 3-Methylenecyclopentene & 2284 & 0.23 & MS, RI \\
\hline 18 & Terpineol-4-ol & 2333 & 4.03 & MS, RI, Co \\
\hline 19 & $\alpha$-Terpineol & 2408 & 2.80 & MS, RI \\
\hline 20 & Bornyl acetate & 1554 & 0.23 & MS, RI \\
\hline 21 & Germacrene D & 2095 & 5.32 & MS, RI, Co \\
\hline 22 & b-Elemen & 2198 & 3.50 & MS, RI \\
\hline 23 & $\beta$-Caryophyllene & 2254 & 9.24 & MS, RI \\
\hline 24 & $\alpha$-Caryophyllene & 2332 & 0.81 & MS, RI \\
\hline 25 & b-cis-Farnesene & 2357 & 3.01 & MS, RI \\
\hline 26 & $\gamma$-Elemene & 2431 & 0.55 & MS, RI \\
\hline 27 & d-Cadinene & 2496 & 0.43 & MS, RI \\
\hline 28 & Ibuprofen & 1930 & 0.37 & MS, RI \\
\hline 29 & (2E,6E)-3,7,11-Trimethyl-9-(phenylsulfonyl)-2,6,10-dodecatrien-1-ol & 2616 & 1.34 & MS, RI \\
\hline 30 & $\alpha$-Bisabolol & 2842 & 0.54 & MS, RI \\
\hline 31 & Chamazulene & 2784 & 5.06 & MS, RI \\
\hline \multirow[t]{2}{*}{32} & 3,3'-Dimethylbiphenyl & 2836 & 0.38 & MS, RI \\
\hline & Total & & 91.74 & \\
\hline
\end{tabular}

${ }^{a}$ Retention index (RI) relative to the homologous series of n-hydrocarbons on the HP-5 MS capillary column.

${ }^{\mathrm{b}}$ Relative area (peak area relative to the total peak area).

${ }^{\mathrm{c}} \mathrm{MS}=$ mass spectrum, $\mathrm{Co}=$ co-injection with standard compound.

The chemical composition of the essential oil of A. argyi aerial parts in the present study was not the same as that reported in previous studies. For example, eucalyptol, (-) -camphor and viridiflorol were the main volatile components of $A$. argyi from Zunyi City, Guizhou Province, China, moreover, the content and composition of the volatile oil of $A$. argyi were various with different growing period $^{36)}$. However, eucalyptol, camphor, and caryophyllene were common constituents in $A$. $\operatorname{argy} i^{37,38)}$. These differences of chemical content and composition of the essential oils might have been due to harvest time and local, climatic and seasonal factors as well as storage duration of medicinal herbs, and these differences may result in different biological activities. 


\subsection{Bioactivity}

3.2.1 Insecticidial activity

3.2.1.1 Contact toxicity

The essential oil of $A$. argyi aerial parts exhibited much stronger contact toxicity against Lasioderma serricorne adults than the four isolated compounds with $\mathrm{LD}_{50}$ value of $6.42 \mu \mathrm{g} / \mathrm{adult}$. When compared with the positive control, pyrethrins $\left(\mathrm{LD}_{50}=0.24 \mu \mathrm{g} / \mathrm{adult}\right)$, the essential oil demonstrated 10 times less toxic against Lasioderma serricorne adults (Table 3). Four constituent compounds, eucalyptol, $\beta$-pinene, $\beta$-caryophyllene and camphor exhibited contact toxicity against Lasioderma serricorne adults, with $\mathrm{LD}_{50}$ values of $15.58,65.55,35.52$ and $11.30 \mu \mathrm{g} /$ adult, respectively (Table 3 ). Moreover, camphor possessed almost 1, 3 and 6 times more toxicity than eucalyptol, $\beta$-caryophyllene and $\beta$-pinene, respectively.

3.2.1.2 Fumigant toxicity

Camphor $\left(\mathrm{LC}_{50}=2.91 \mathrm{mg} / \mathrm{L}\right.$ air $)$ exhibited stronger fumigant toxicity against Lasioderma serricorne adults than eucalyptol $\left(\mathrm{LC}_{50}=5.18 \mathrm{mg} / \mathrm{L}\right.$ air $)$ and the crude essential oil of $A$. argyi aerial parts $\left(\mathrm{LC}_{50}=8.04 \mathrm{mg} / \mathrm{L}\right.$ air $)$, while $\beta$-pinene showed a $\mathrm{LC}_{50}$ value of $29.03 \mathrm{mg} / \mathrm{L}$ air (Table 4 ). However, $\beta$-caryophyllene did not show fumigant toxicity at the tested concentrations. Camphor showed almost 2, 3 and 10 times stronger fumigant toxicity than eucalyptol, the crude essential oil and $\beta$-pinene against Lasioderma serricorne adults, respectively. Compared with the posi- tive control, phosphine $\left(\mathrm{LC}_{50}=9.23 \times 10^{-3} \mathrm{mg} / \mathrm{L}\right.$ air $)$, camphor exhibited weaker fumigant toxicity against $L$. serricorne adults, eucalyptol, the crude essential oil and $\beta$-pinene exhibited much less toxicity to $L$. serricorne adults. However, when compared with other essential oils, A. argyi essential oil possessed stronger fumigant toxicity against Lasioderma serricorne adults, e.g. essential oils of Elsholtzia stauntonii $\left(\mathrm{LD}_{50}=10.99 \mu \mathrm{L} / \mathrm{L}\right)^{39)}$.

The currently used fumigants are synthetic insecticides and the most effective fumigants (e.g., phosphine and methyl bromide) are also highly toxic to humans and other non-target organisms, the essential oil of $A$. argyi aerial parts and its isolated constituent compounds show potential to be developed as possible natural fumigants or insecticides for the control of Lasioderma serricorne adults. However, for the practical application of the essential oil and the isolated constituents as novel insecticides or fumigants, further studies on the safety of the essential oil to humans and on development of formulations are necessary to improve the efficacy and stability and to reduce costs. 3.2.2 Repellent activity

Artemisia argyi essential oil and three isolated constituents exhibited strong repellent activity against $L$. serricorne adults. The results presented in Fig. 2. Data showed that at tested concentration of $39.32 \mathrm{~nL} / \mathrm{cm}^{2}$, the crude essential oil showed strongest (class $\mathrm{V}$ ) repellency against Lasioderma serricorne adults at $2 \mathrm{~h}$ and $4 \mathrm{~h}$ after expo-

Table 3 Contact toxicity of the essential oil of $A$. argyi aerial parts and its constituents against Lasioderma serricorne adults.

\begin{tabular}{cccccc}
\hline Insects & Treatment & $\mathrm{LD}_{50}(\mu \mathrm{g} /$ adult $)$ & $95 \% \mathrm{FL} *$ & Slope $\pm \mathrm{SE}$ & Chisquare $\left(\chi^{2}\right)$ \\
\hline & Artemisia argyi & 6.42 & $5.62-7.32$ & $2.25 \pm 0.30$ & 15.13 \\
& Eucalyptol & 15.58 & $12.88-18.02$ & $3.87 \pm 0.55$ & 15.18 \\
Lasioderma & $\beta$-Pinene & 65.55 & $58.13-76.09$ & $3.75 \pm 0.46$ & 21.62 \\
serricorne & Camphor & 11.30 & $7.78-14.07$ & $1.47 \pm 0.28$ & 16.13 \\
& $\beta$-Caryophyllene & 35.52 & $31.89-39.54$ & $3.07 \pm 0.37$ & 15.41 \\
& Pyrethrins ** & 0.24 & $0.16-0.35$ & $1.31 \pm 0.20$ & 17.36 \\
\hline
\end{tabular}

* Fiducial limits, $* *$ data from Yang ${ }^{40)}$.

Table 4 Fumigant toxicity of the essential oil of $A$. argyi aerial parts and its constituents against Lasioderma serricorne adults.

\begin{tabular}{cccccc}
\hline Insects & Treatment & $\mathrm{LC}_{50}(\mathrm{mg} / \mathrm{L}$ air $)$ & $95 \% \mathrm{FL} *$ & Slope $\pm \mathrm{SE}$ & Chisquare $\left(\chi^{2}\right)$ \\
\hline & Artemisia argyi & 8.04 & $7.00-9.22$ & $2.22 \pm 0.30$ & 8.84 \\
& Eucalyptol & 5.18 & $4.63-5.70$ & $4.84 \pm 0.59$ & 16.79 \\
Lasioderma & $\beta$-Pinene & 29.03 & $26.38-31.79$ & $5.41 \pm 0.58$ & 17.48 \\
serricorne & Camphor & 2.91 & $2.57-3.26$ & $2.72 \pm 0.34$ & 13.11 \\
& $\beta$-Caryophyllene & - & - & - & - \\
& Phosphine $* *$ & $9.23 \times 10^{-3}$ & $7.13 \times 10^{-3}-11.37 \times 10^{-3}$ & $2.12 \pm 0.27$ & 11.96 \\
\hline
\end{tabular}

* Fiducial limits, ** data from Yang ${ }^{40)}$. 

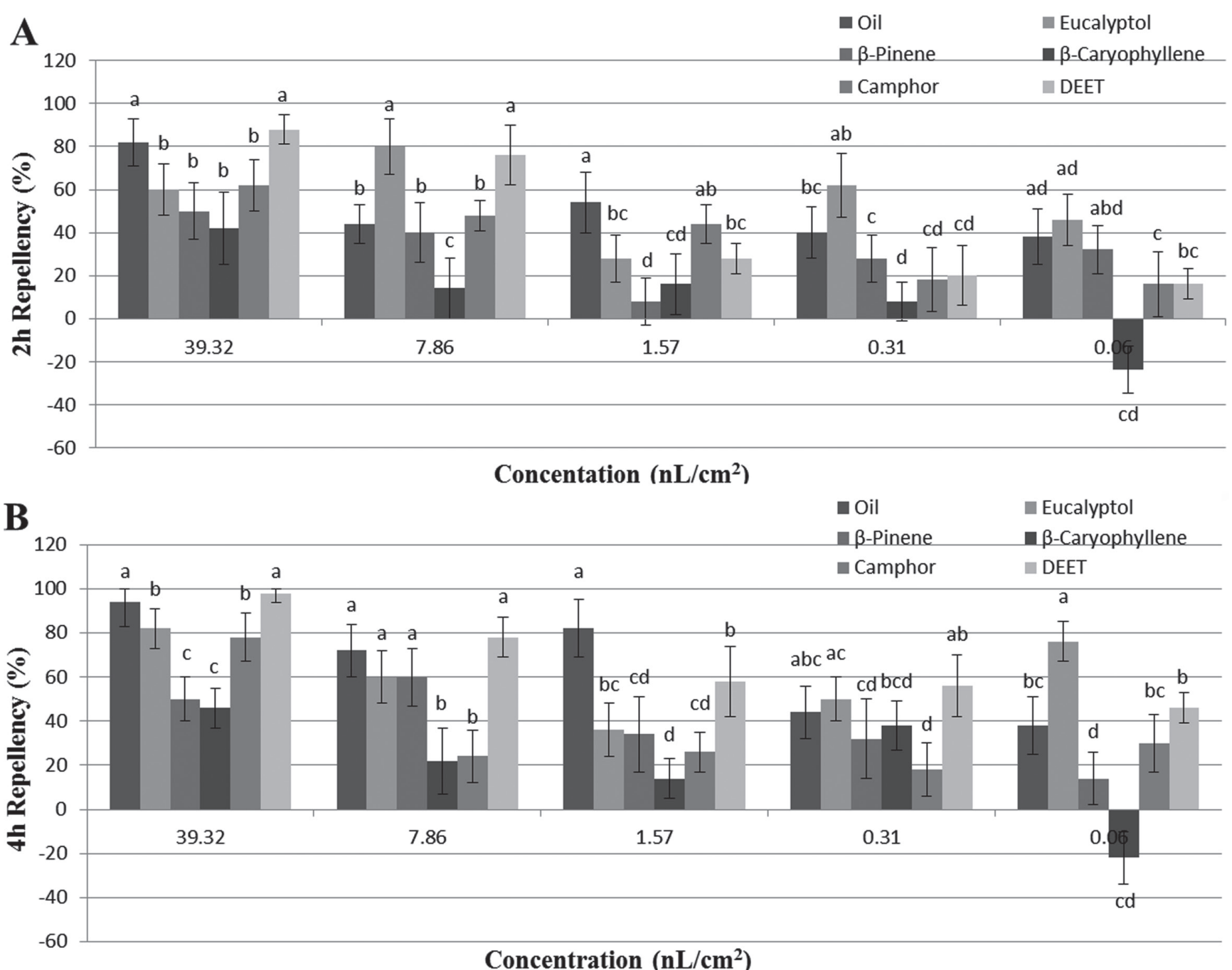

Fig. 2 Percentage repellency (PR) of the essential oil from A. argyi aerial parts and its constituents against Lasioderma serricorne at $2 \mathrm{~h}(\mathrm{~A})$ and $4 \mathrm{~h}(\mathrm{~B})$ after exposure ${ }^{\mathrm{a}}$.

${ }^{a}$ means in the same column followed by the same letters do not differ significantly $(p>0.05)$ in ANOVA and Tukey's tests. PR was subjected to an arcsine square-root transformation before ANOVA and Tukey's tests.

sure. At the lowest assayed concentration $\left(0.06 \mathrm{~nL} / \mathrm{cm}^{2}\right)$, eucalyptol showed much stronger (class IV) repellency (76\%) than the positive control, DEET (class III, $P R=$ $46 \%)$ at $4 \mathrm{~h}$ after exposure against Lasioderma serricorne adults. Compared with the positive control, DEET, the essential oil and eucalyptol exhibited stronger repellency against Lasioderma serricorne adults, because at the concentrations of $1.57,0.31$ and $0.06 \mathrm{~nL} / \mathrm{cm}^{2}$, the essential oil and eucalyptol exhibited higher level of repellency against Lasioderma serricorne adults at $2 \mathrm{~h}$ after exposure, and at the concentrations of $0.06 \mathrm{~nL} / \mathrm{cm}^{2}$, the essential oil, eucalyptol and $\beta$-pinene exhibited the same and higher level of repellency than DEET against Lasioderma serricorne adults at the concentrations of 0.31 and 0.06 $\mathrm{nL} / \mathrm{cm}^{2}$ at $2 \mathrm{~h}$ after exposure. However, $\beta$-caryophyllene even exhibited attracting action against Lasioderma ser- ricorne adults at the concentrations of $0.06 \mathrm{~nL} / \mathrm{cm}^{2}$ at $2 \mathrm{~h}$ and $4 \mathrm{~h}$ after exposure. And more remarkably, camphor showed a decrease in repellency against Lasioderma serricorne adults at the concentrations of 1.57 and $7.86 \mathrm{~nL} /$ $\mathrm{cm}^{2}$ at $4 \mathrm{~h}$ after exposure, compared with the repellent activity at $2 \mathrm{~h}$ after exposure. It might be attributed to its non-persistent volatility. However, there's on sufficient reports about it at present. Hence, further studies would be conducted in the future. In this paper, we report to isolate four repellent constituents from the essential oil of Artemisia argyi aerial parts against $L$. serricorne adults for the first time. 


\section{CONCLUSION}

To the best of our knowledge, this report is the first one to demonstrate the biocontrol of $A$. argyi essential oil. The chemical composition of this essential oil was described in detail and appreciable bioactivity of the oil and its major constituents were also demonstrated. The results suggested that $A$. argyi essencial oil and its major constituents have potential uses in the study of ecological prevention and control of storage pests. Since the natural resources of A. argyi are abundant, further investigations that focus on more detailed biological activity studies should be conducted to elucidate the bioactivity mechanism of tested essential oils for various applications.

\section{ACKNOWLEDGMENT}

This project was supported by the National Natural Science Foundation of China(No. 81374069) and Beijing Municipal Natural Science Foundation(No. 7142093).

\section{REFERENCES}

1) Ashworth, J. R. The biology of Lasioderma serricorne. J. Stored. Prod. Res. 29, 291-303 (1993).

2) Ebadollahi, A.; Safaralizadeh, M.; Pourmirza, A.; Gheibi, S. Toxicity of Essential Oil of Agastache Foeniculum(Pursh) Kuntze to Oryzaephilus Surinamensis L. and Lasioderma Serricorne F. J. Plant Protec. Res. 50, 215-219(2010).

3) Phillips, T. W.; Throne, J. E. Biorational approaches to managing stored-product insects. Annu. Rev. Entomol. 55, 375 (2009).

4) Isman, M. B. Botanical insecticides, deterrents, and repellents in modern agriculture and an increasingly regulated world. Annu. Rev. Entomol. 51, 45-66 (2006).

5) Rajendran, S.; Sriranjini, V. Plant products as fumigants for stored-product insect control. J. Stored. Prod. Res. 44, 126-135(2008).

6) Ahmadi, M.; Abd-alla, A. M. M.; Moharramipour, S. Combination of gamma radiation and essential oils from medicinal plants in managing Tribolium castaneum contamination of stored products. Appl. Radiat. Isotopes 78, 16-20 (2013).

7) Chu, S. S.; Liu, S. L.; Liu, Q. Z.; Jiang, G. H.; Liu, Z. L. Chemical composition and insecticidal activities of the essential oil of the flowering aerial parts of Aster ageratoides. J. Serb. Chem. Soc. 78, 209-216(2013).

8) Fang, R.; Jiang, C. H.; Wang, X.Y .; Zhang, H. M.; Liu, Z. L.; Zhou, L. G.; Du, S. S.; Deng, Z. W. Insecticidal activity of essential oil of Carum carvi fruits from China and its main components against two grain storage in- sects. Molecules 15, 9391-9402(2010).

9) Liang, Y.; Li, J. L.; Xu, S.; Zhao, N. N.; Zhou, L.; Cheng, J.; Liu, Z. L. Evaluation of repellency of some Chinese medicinal herbs essential oils against Liposcelis bostrychophila (Psocoptera: Liposcelidae) and Tribolium castaneum (Coleoptera: Tenebrionidae). J. Econ. Entomol. 106, 513-519(2013).

10) Liu, Z. L.; Zhao, N. N.; Liu, C. M.; Zhou, L.; Du, S. S. Identification of insecticidal constituents of the essential oil of Curcuma wenyujin rhizomes active against Liposcelis bostrychophila Badonnel. Molecules 17, 12049-12060 (2012).

11) Liu, Z. L.; Du, S. S. Fumigant components from the essential oil of Evodia rutaecarpa Hort unripe fruits. J. Chem. 8, 1937-1943(2011).

12) Liu, Z. L.; Liu, S. L.; Yang, K.; Chu, S. S.; Liu, Q. Z.; Du, S. S. Chemical composition and toxicity of essential oil of Boenninghausenia sessilicarpa (Rutaceae) against two grain storage insects. J. Med. Plants Res. 6, 2920-2924 (2012).

13) Lu, J.; Su, X.; Zhong, J. Fumigant activity of Elsholtzia stauntonii extract against Lasioderma serricorne: research letter. S. Afr. J. Sci. 108, 1-3(2012).

14) Zhang, J. S.; Zhao, N. N.; Liu, Q. Z.; Liu, Z. L.; Du, S. S.; Zhou, L.; Deng, Z. W. Repellent constituents of essential oil of Cymbopogon distans aerial parts against two stored-product insects. J. Agr. Food Chem. 59, 9910-9915(2011).

15) Zhao, N. N.; Zhou, L.; Liu, Z. L.; Du, S. S.; Deng, Z. W. Evaluation of the toxicity of the essential oils of some common Chinese spices against Liposcelis bostrychophila. Food Control. 26, 486-490(2012).

16) Becnel, J. J.; Tsikolia, M.; Bernier, U. R.; Tabanca, N.; Baser, K. H.; Wedge, D. E.; Agramonte, N. M.; Sakhanokho, H. F.; Sampson, B. J.; Demirci, B. Chemical Composition, Antifungal and Insecticidal Activities of Hedychium Essential Oils. Molecules 18, 4308-4327 (2013).

17) Hsouna, A. B.; Halima, N. B.; Abdelkafi, S.; Hamdi, N. Essential oil from Artemisia phaeolepis: chemical composition and antimicrobial activities. J. Oleo Sci. 62, 973-980 (2012).

18) Wang, J.; Zhao, J.; Liu, H.; Zhou, L.; Liu, Z.; Wang, J.; Han, J.; Yu, Z.; Yang, F. Chemical analysis and biological activity of the essential oils of two valerianaceous species from China: Nardostachys chinensis and Valeriana officinalis. Molecules 15, 6411-6422(2010).

19) Chen, X. B.; Liu, X. C.; Zhou, L.; Liu, Z. L. Essential Oil Composition and Larvicidal Activity of Clinopodium gracile (Benth) Matsum (Labiatae) Aerial Parts against the Aedes albopictus Mosquito. Trop. J. Pharm. Res. 12, 799-804 (2013).

20) Liu, Z. L.; Liu, Q. Z.; Du, S. S.; Deng, Z. W. Mosquito larvicidal activity of alkaloids and limonoids derived 
from Evodia rutaecarpa unripe fruits against Aedes albopictus (Diptera: Culicidae). Parasitol. Res. 111, 991-996 (2012).

21) Liu, X. C.; Dong, H. W.; Zhou, L.; Du, S. S.; Liu, Z. L. Essential oil composition and larvicidal activity of Toddalia asiatica roots against the mosquito Aedes albopictus (Diptera: Culicidae). Parasitol. Res. 112, 1197-1203 (2013).

22) Isman, M. B. Plant essential oils for pest and disease management. Crop Prot. 19, 603-608(2000).

23) Li, N.; Mao, Y.; Deng, C.; Zhang, X. Separation and Identification of Volatile Constituents in Artemisia argyi Flowers by GC-MS with SPME and Steam Distillation. J. Chromatogr. Sci. 46, 401-405(2008).

24) Guan, W. Q.; Li, S. F.; Yan, R. X.; Huang, Y. F. Comparison of composition and antifungal activity of Artemisia argyi Levl. et Vant inflorescence essential oil extracted by hydrodistillation and supercritical carbon dioxide. Nat. Prod. Res. 20, 992-998(2006).

25) Kim, J. H.; Kim, H.; Jeon, S. B.; Son, K.; Kim, E. H.; Kang, S. K.; Sung, N.; Kwon, B. New sesquiterpenemonoterpene lactone, artemisolide, isolated from Artemisia argyi. Tetrahedron Lett. 43, 6205-6208(2002).

26) Bian, R. Antiasthmatic action and components of the Chinese herb Artemisia argyi. Eur. J. Pharmacol. 183, 226-227 (1990).

27) Ramsey, L. L.; Patterson, W. I. Separation and identification of the volatile saturated fatty acids (C1 to $\mathrm{C} 4)$. J. Assoc. Official Agric. Chem. 28, 644-656 (1945).

28) Adam, R. P. Identification of essential oil components by gas chromatography/quadrupole mass spectrometry. J. Am. Soc. Mass Spectrom 16, 1902-1903(2005).

29) Ashnagar, A.; Naseri N. G.; Bayemani, A. Isolation and determination of the major chemical compounds present in essential oil of the leaves of Myrtus plant grown in Khuzestan Province of Iran. Asian J. Chem. 21, 4969-4975 (2009).

30) Badjah Hadj Ahmed, A. Y.; Meklati, B. Y.; Waton, H.; Pham, Q.T. Structural studies in the bicyclo[3.1. 1] heptane series by ${ }^{1} \mathrm{H}$ and ${ }^{13} \mathrm{C}$ NMR. Magn. Reson. Chem. 30, 807-816 (1992).
31) Tanaka, H; Chou, J. Y.; Mine, M.; Kuroboshi, M. The oxidation of alcohols in N-oxyl-immobilized silica gel/ aqueous $\mathrm{NaOCl}$ disperse systems. A prominent access to a column-flow system. Bull. Chem. Soc. Jpn. 77, 1745-1755 (2004).

32) Ragasa, C. Y.; Espineli, D. L.; Agoo, E.; Del Fierro, R. S. Chemical constituents of Cinnamomum cebuense. Chin. J. Natural Med. 11, 264-268(2013).

33) Liu, Z. L.; Ho, S. H. Bioactivity of the essential oil extracted from Evodia rutaecarpa Hook f. et Thomas against the grain storage insects, Sitophilus zeamais Motsch and Tribolium castaneum (Herbst). J. Stored Prod. Res. 35, 317-328(1999).

34) Sakuma, M., Probit analysis of preference data. Appl. Entomo. Zool. 33, 339-348(1998).

35) Nerio, L. S.; Olivero-Verbel, J.; Stashenko, E. Repellent activity of essential oils: A review. Bioresource Technol. 101, 372-378(2010).

36) Hong, Z. G.; Wei, H. S.; Zhang, L. L.; LYU, F.; Wu, H. Study on the yield and chemical components of thevolatile oil from Artemisiae argyi Levl. et Vant. gathered in different growing period. J. South-Central Univ. Nation. 32, 32-35 (2013).

37) Lan, M. B.; Yu, Y. L.; Li, X. H. Analysis on the chemical constituents of the essential oil of Artemisia argyi Levl. et Vant . in Guizhou. Chin. J. Pharm. Anal. 29, 1305-1308 (2009).

38) He, Z. Y.; Zhang, Y. H.; Wei, D.; Yu, R. H.; Yuan, H. H.; Lan, M. B. Chemical composition of essential oil from fresh and dried Folium Artemisia argyi from Hubei Province. Chin. Trad. Patent Med. 31, 1079-1082 (2009).

39) Lu, J. H.; Su, X. H.; Zhang, J. J. Fumigant activity of Elsholtzia stauntonii extract against Lasioderma serricorne. S. Afr. Sci. 108, 77-79(2012).

40) Yang, K.; Wang, C. F.; You, C. X.; Geng, Z. F.; Sun, R. Q.; Guo, S. S.; Du, S. S.; Liu, Z. L.; Deng, Z. W. Bioactivity of essential oil Litsea cubeba from China and its main compounds against two stored product insects. $J$. Asia-Pacific Ent. 17, 459-466 (2014). 